\title{
On the Species Upogebia stellata and Gebia deltura.
}

\author{
By
}

W. De Morgan, F.Z.S.

As remarked by Stebbing (A History of Recent Crustacea, p. 185): "Upogebia, Leach, 1814, was founded to receive another species discovered by the industrious Montagu, and described by him in 1805 (1808) as Cancer astacus stellatus. . . . It seems to have escaped the notice of writers subsequent to Leach that the earliest name of this genus was Upogebia, which therefore must be retained in preference to Leach's own alteration of it into Gebia, or Risso's Gebios."

Some doubt still appears to exist whether Upogebia stellata (Leach) and Gebia deltura (Leach) are distinct, or merely sexual forms of the same species.

Leach gives excellent figures of Gebia stellata (Malac. Podolph. Brit., table xxi, figs. 1-9) and Gebia deltura (figs. 9-10). He regarded them as distinct species, and remarks of Gebia deltura: "This species lives with Gebia stellata, with which it was confounded, until the distinctions were discovered by Mr. J. D. C. Sowerby." I am unable to find out whether Mr. Sowerby recorded his description.

Bell (British Stalk-eyed Crustacea, pp. 223-5) describes Gebia stellata and Gebia deltura under the genus Gebia (Leach), of the Thalassinidæ, and gives good figures of both. He appears to doubt, however, whether they are distinct species, and of $G$. deltura writes: "This species, if it be indeed distinct, differs from the former, $G$. stellata, in the following particulars: the whole animal is very much larger, sometimes not less than twice the length, and more than proportionately wider. The carapace is much broader and more spreading at the sides. The legs are more robust ; the arm of the first pair is not more than twice as long as it is broad, the wrist even shorter than broad, the hand thicker, and the fingers more nearly of equal length. The seta of the external antennæ are shorter in proportion, being, according to Leach's figure, not more than half the length of the body. The abdomen is broader, more spread, and much less firm in its texture, the sides being almost membranaceous, and the abdominal false feet larger and more voluminous than in the other species. The different lamellæ of the 
tail differ also in some particulars, the exterior being rather broader than it is long, and the middle one, or terminal segment, of the abdomen nearly quadrate. In all other respects the two species very greatly resemble each other."

In a note Bell remarks: "The term 'deltoid' appears to be very much misplaced in describing this part."

If Leach referred to the central lamella of the tail, the term is misleading, as that plate is certainly subquadrate in form. But, as pointed out by Stebbing (History of Crustacea, p. 186), Leach was no doubt referring to the minor branch of the Uropods, which may reasonably be described as "deltoid."

Bell further remarks: "I confess I am very doubtful if it will not prove on further investigation that the two British forms, and perhaps also G. littoralis of Risso, constitute but one species. The form and development of the abdomen, and the great development of the abdominal false feet in $G$. deltura, are certainly very much like peculiarities belonging to the female sex, and calculated for the support and protection of the ova."

Norman appears to consider that there is only one species. In his Crustacea of Devon and Cornwall, p. 12, he has:-

\section{"Upogebia stellata (Montagu) = Gebia deltura (Leach)."}

At the Marine Biological Laboratory, Plymouth, I have had the opportunity of examining a good many specimens of both forms, both alive and in spirit. The two forms are always found together at Salcombe, and a day's hunting may produce a dozen specimens. Stellata is rather more common than delturc.

I have kept several of the stellata form in berry under circulation, and the zoæas have hatched out, and one specimen of the deltura form, in berry, which also hatched. In neither case, however, was I able to rear the larvæ. There are thus males and females of both forms. The genital opening of both forms is situated in the females on the basipodite of the 3rd thoracic appendage, and is covered by a diaphragm. It is very easy to see. In the males, the opening is on the basipodite of the 5th thoracic segment. Close to it, there is a small tuft of setæ. It is not so easy to distinguish as in the female.

The females of both forms possess modified copulatory appendages, and may be recognised by them, as they are absent in the males.

Among the Thalassinidæ, Upogebia forms a rare exception to the general rule on this point (vide Calman, in Treatise of Zoology, ed. by Ray Lankester, part vii, p. 274). 
In large specimens it is easy to distinguish between deltura and stellata. The width of the abdominal plates in deltura is very noticeable, and the rostrum is blunter. It is altogether a more massive animal, and the spotted appearance, whence the name stellata,

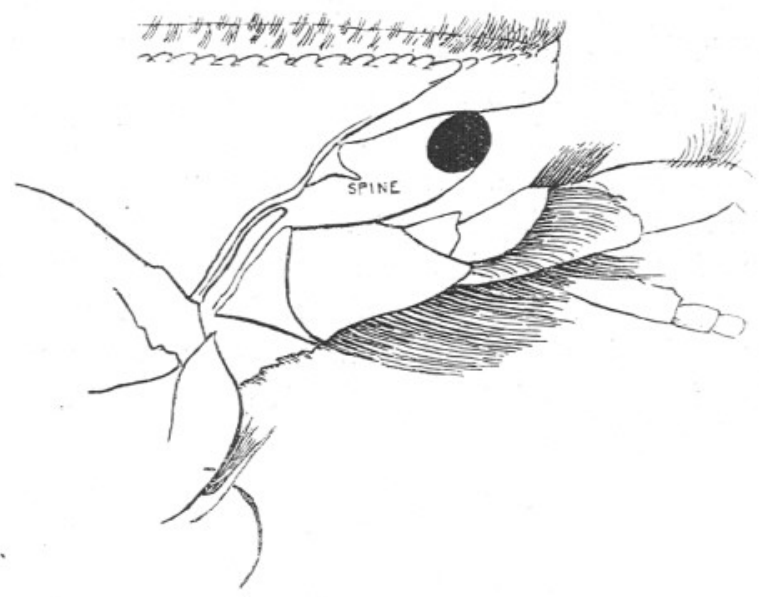

Fig. 1.-Upogebia stellata, showing spine. Cam. luc. $\times 27$.

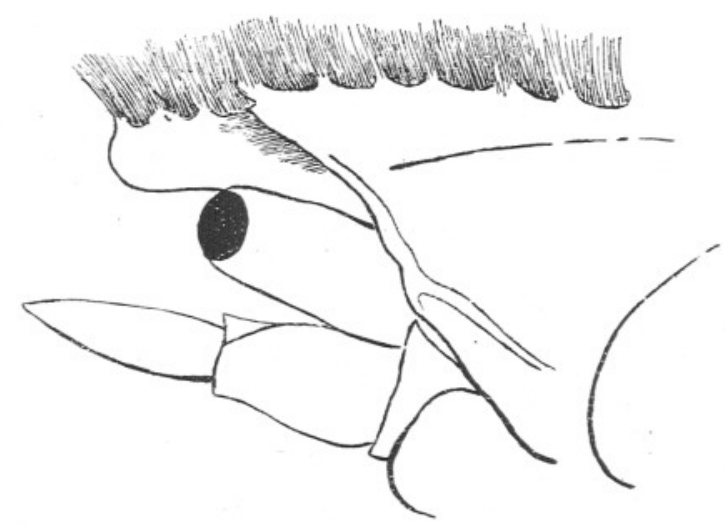

FIG. 2.-Gebia deltura.

Cam. luc. $\times 27$.

is wanting. In deltura the dactylopod is stouter and blunter, and more nearly equals the process of the propodite in length. On the inner side, where the dactylopod hinges, there are two blunt spines. In stellata the "fingers" are much slighter, the dactylopod longer and slenderer, and the opposite process smaller, than in deltura. 
The hairs on the rostrum and carapace, and also on the edges of the abdominal plates, are longer and thicker in deltura than in stellata, and give it a more shaggy appearance.

In small specimens, however, these differences are not so marked. But stellata has one mark which always distinguishes it from deltura, namely, a small spine on the curved edge of the frontal margin of the carapace behind the eye-stalks. In ordinary specimens it is easily seen; in very small ones a lens may be required to detect it, but its presence in stellata is constant. In deltura it is absent, and the margin of the carapace forms an unbroken curve. The spine is shown in the figure ( $c f$. Figs. 1 and 2).

This spine is not shown in the figures of either Leach or Bell. It would hardly be visible on so small a scale; also, it would hardly be seen in the position in which the animal is drawn. From the above considerations it appears that Upogebia stellata and Gebia deltura are clearly distinct species. 